\section{Localized lymphadenopathy with myelodysplastic syndrome associated with tuberculosis}

Aya Nakaya, ${ }^{1}$ Kazuyoshi Ishii, ${ }^{1}$

Toshiki Shimizu, ${ }^{1}$ Takeshi Tamaki, ${ }^{1}$

Yoshihisa Ishiura, ${ }^{1}$ Mayumi Inaba, ${ }^{2}$

Yoshiko Uemura, ${ }^{2}$

Hirokazu Nakamine, ${ }^{3}$ Shosaku Nomura ${ }^{1}$

${ }^{1}$ First Department of Internal

Medicine, Kansai Medical University

Medical Center, Osaka; ${ }^{2}$ Departments of

Pathology and Laboratory Medicine,

Kansai Medical University Medical

Center, Osaka; ${ }^{3}$ Department of

Pathology, The Japan Baptist Hospital,

Kyoto, Japan

\begin{abstract}
We report the case of a man who developed myelodysplastic syndrome (MDS) and refractory cytopenia of unilineage dysplasia, 5 months after aortic valve replacement surgery. $\mathrm{He}$ also developed fever of unknown origin. After bone marrow- and other laboratory examinations, he was diagnosed with tuberculosis.
\end{abstract}

\section{Case Report}

A 58-year-old man underwent aortic valve replacement surgery in March 2018. Five months after the operation, he developed anemia and blasts appeared in a peripheral blood test (white blood cell count $7800 / \mu \mathrm{L}$, hemoglobin $8.4 \mathrm{~g} / \mathrm{dL}$, platelet count $15.4 \times 10^{4} / \mu \mathrm{L}$, blasts $\left.1.5 \%\right)$. He underwent bone marrow examination (BME) (nucleated cell count [NCC] $5.0 \times 10^{4} / \mu \mathrm{L}$, blasts $3.7 \%$, ringed sideroblasts $53.0 \%$ ), and was diagnosed with myelodysplastic syndrome (MDS) and refractory cytopenia of unilineage dysplasia (RCUD) without any cytogenetic abnormality. After the examination, he arrived at the hospital with high-grade fever $\left(38.5^{\circ} \mathrm{C}\right)$ and no other symptoms. Laboratory examination revealed anemia without progression. To rule out progression of MDS, he underwent BME again; however, the blast count was $4.0 \%$ (NCC $5.0 \times 10^{4} / \mu \mathrm{L}$ ), unchanged from the previous BME.

To rule out infection focus we performed a computed tomography (CT) scan, which showed extensive lymphadenopathy in the paratracheal region without pulmonary infiltration (Figure 1). We suspected infection of the upper respiratory tract; however, all cultures were negative. Despite starting the patient on empiric antibiotics, the fever persisted for a week. He then underwent mediastinal lymph node biopsy by thoracoscope. Histopathologic examination showed granulamatous lymphadenitis with necrosis including multinucleated giant cells, mostly suggesting tuberculosis (TB) (Figure 2). Upon Ehrlich-Ziehl-Neelsen staining, both Mycobacterium tuberculosis and interferongamma release assay (QuantiFeron $\left.{ }^{\circledR}\right)$ were positive. After a course of isoniazid, rifampicin, and ethambutol, the patient's fever resolved and the lymphadenopathy disappeared.
Correspondence: Aya Nakaya, First Department of Internal Medicine, Kansai Medical University Medical Center, 10-15, Fumizono-cho, Moriguchi, Osaka 570-8507, Japan.

Tel.: +81.6-6992-1001.

E-mail: nakaya1016@yahoo.co.jp

Key words: Lymphoadenopathy, myelodysplastic syndromes, tuberculosis.

Contributions: the authors contributed equally.

Conflict of interest: the authors declare no potential conflict of interest.

Funding: none.

Received for publication: 13 April 2019.

Revision received: 9 August 2019.

Accepted for publication: 21 August 2019.

This work is licensed under a Creative Commons Attribution-NonCommercial 4.0 International License (CC BY-NC 4.0).

CC Copyright: the Author(s), 2019

Licensee PAGEPress, Italy

Hematology Reports 2019; 11:8147

doi:10.4081/hr.2019.8147

\section{Discussion and Conclusions}

MDS is a group of clonal myeloid disorders that often progress to acute leukemia. Pancytopenia is a common finding. Cell-mediated immunity is seriously impaired and patients are predisposed to infections, which account for

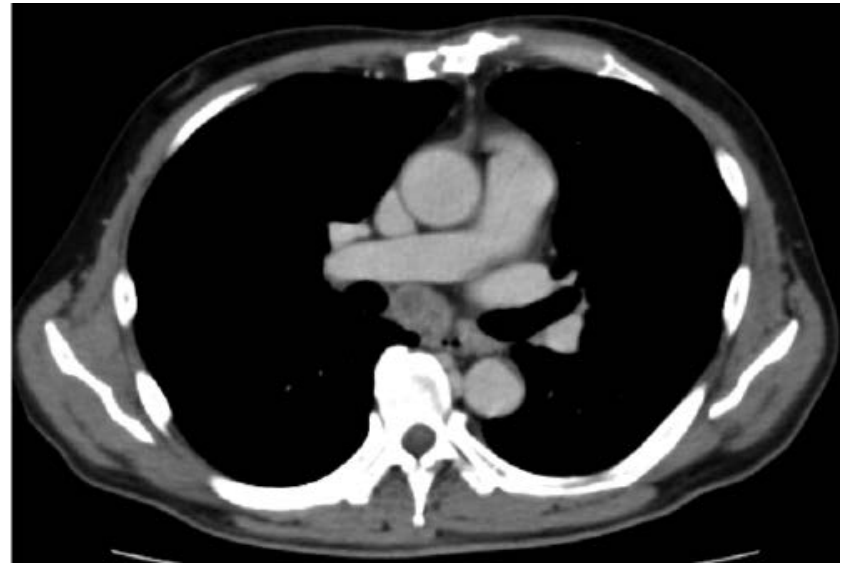

Figure 1. Enhanced computed tomography revealed mediastinal lymphadenopathy.

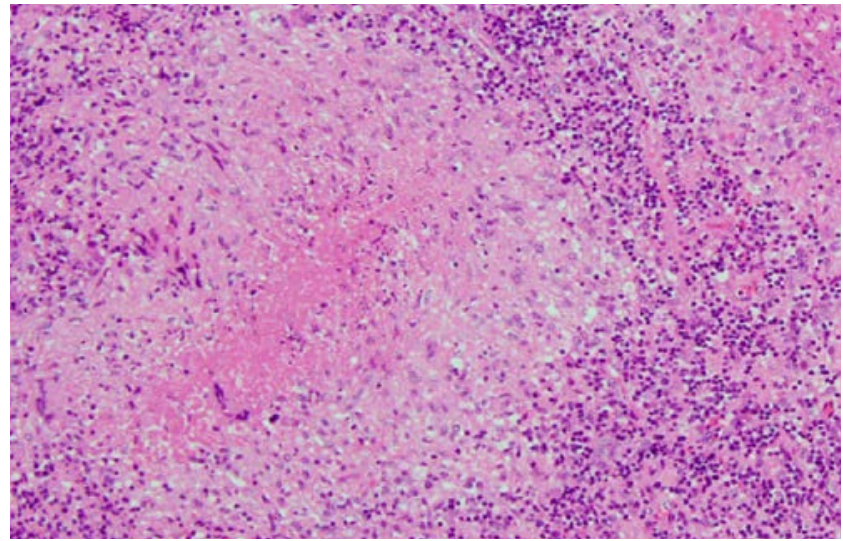

Figure 2. Caseous granuloma including multinucleated giant cell, indicating tuberculosis. Hematoxylin eosin stain, original magnification $\times 100$. 
about one-third of deaths. MDS cases with TB represent $10.5 \%$ of the total number of patients diagnosed with TB and hematologic malignancy. ${ }^{1}$ In other reports, $7.2-7.7 \%$ of $\mathrm{TB}$ patients suffered from MDS. ${ }^{2,3}$ Recently, a large population-based cohort study was published that investigated 495,335 cancer patients, among whom 148.8 out of 100,000 MDS/MPN patients developed TB. The investigators cautioned that patients with a background of MDS/MPN have a higher risk of developing TB. ${ }^{4}$ The major host defense against TB is cell-mediated immunity. It has been reported that there are serious defects in the lymphoid system in addition to abnormalities in the myeloid populations of MDS patients, such as decreased absolute numbers of $T$ lymphocytes and markedly decreased CD4+/CD8+ ratio. $^{5}$

Because our patient underwent aortic valve replacement surgery before he developed fever, we at first suspected infection affecting the operation site. CT showed lymphadenopathy without lung lesions, which led us to suspect infection around the respiratory tract. Previous studies reported that the right paratracheal region was the most frequently involved nodal site in immunocompetent and immunocompromised patients with TB. ${ }^{6}$ Kim et al. investigated 195 MDS patients and revealed 12 TB patients in this cohort, $50 \%$ of whom had extrapulmonary involvement. ${ }^{4}$ Thus, the initial symptom of TB appears to be extrapulmonary, which may be common in an immunocompromised host.

Our patient presented with a fever of unknown origin (FUO). Generally, TB is considered to be one of the most common infections to produce FUO, although it never occurred to us because of the patient's disparate clinical history. For this reason, we must encourage awareness that TB may be a common infection in MDS, and should thus be considered in the differential diagnosis of patients with MDS presenting with any type of lymphadenopathy.

\section{References}

1. De La Rosa GR, Jacobson KL, Rolston $\mathrm{KV}$, et al. Mycobacterium tuberculosis at a comprehensive cancer centre: active disease in patients with underlying malignancy during 1990-2000. Clin Microbiol Infect 2004;10:749-52.

2. Silva FA, Matos JO, de Q Mello FC, Nucci M. Risk factors for and attributable mortality from tuberculosis in patients with hematologic malignances. Haematologica 2005;90:1110-5.

3. Kim HC, Goo JM, Kim HB, et al. Tuberculosis in patients with myelodysplastic syndromes. Clin Radiol 2002;57:408-14.

4. Ganzel C, Silverman B, Chemtob D, et al. The risk of tuberculosis in cancer patients is greatest in lymphoma and myelodysplastic syndrome/myeloproliferative neoplasm: a large populationbased cohort study. Leuk Lymphoma 2018:1-6

5. Bynoe AG, Scott CS, Ford P, Roberts BE. Decreased $\mathrm{T}$ helper cells in the myelodysplastic syndromes. $\mathrm{Br} \mathrm{J}$ Haematol 1983;54:97-102.

6. Im JG, Song KS, Kang HS, et al. Mediastinal tuberculous lymphadenitis: CT manifestations. Radiology 1987 ;164:115-9. 